\title{
The sexual and reproductive health of young people in Latin America: Evidence from $\mathbb{W H} 0$ case studies
}

\author{
Kate Kostrzewa, JD, PhD.
}

\begin{abstract}
Kostrzewa K.
The sexual and reproductive health of young people in Latin America: Evidence from WHO case studies. Salud Publica Mex 2008;50:10-16.
\end{abstract}

\section{Kostrzewa K.}

La salud sexual y reproductiva de los jóvenes en América Latina: evidencia derivada de estudios de la OMS. Salud Publica Mex 2008;50:10-16.

\section{Resumen}

Este artículo original trata de las necesidades de salud sexual y reproductiva de jóvenes entre 15 y 24 años de edad en América Latina. Se presentan cuatro artículos derivados de investigaciones originales en tres países: Argentina, Brasil y Perú. Estos proyectos fueron patrocinados por la Organización Mundial de la Salud. Este artículo elucida la importancia de los estudios que tratan de la salud sexual y reproductiva de jóvenes en países en desarollo. Se ilustra el panorama general en cuestiones de salud sexual y reproductiva en América Latina y una discusión de estas cuestiones en los tres países de donde provienen los estudios. Los cinco artículos discuten cuestiones difíciles y controversiales, como los conocimientos sobre ITS y VIH/SIDA; las prácticas asociadas con el parto; la calidad de cuidados; el papel de los hombres jóvenes en la formación de parejas, el embarazo y el uso de métodos anticonceptivos; así como el papel de los tocólogos y ginecólogos en el debate público sobre planificación familiar y aborto. Los cuatro artículos en esta sección especial promueven un mejor entendimiento de los factores que contribuyen a las conductas sexuales de riesgo y a los resultados negativos en salud reproductiva entre los jóvenes en América Latina. Las conclusiones son útiles para informar y mejorar intervenciones de servicios de salud en contextos varios.

Palabras clave: adolescentes; salud sexual; salud reproductiva; América Latina

\begin{abstract}
Keywords: adolescents; sexual health; reproductive health; Latin America

help inform and improve health care interventions in various contexts.

This original article addresses the sexual and reproductive It introduces five articles from original research projects in three countries: Argentina, Brazil, and Peru. These projects explains the importance of studies that address the sexual and 作 gynecologists in public policy debate about family planni and abortion. The four articles in this special section help to the factors that contribu to risky sexual behavior and negative reproductive heat outcomes among youth in Latin America. The findings are
\end{abstract}

\section{Latin America}

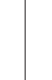


$\mathrm{T}^{\mathrm{s}}$ he World Health Organization's (WHO) Department of Reproductive Health and Research solicits grant proposals each year for research addressing adolescent sexual and reproductive health (ASRH). WHO funding is awarded based on the recommendations of scientific and technical advisory committees. The papers selected for this volume were drawn from a set of fifteen WHO funded ASRH studies undertaken in seven Latin American countries. ${ }^{*}$ The research addressed a range of topics, including service provision; behaviors and knowledge; risk perception; emotional health; negotiation skills; male involvement; condom use; social support networks; STIs and HIV/AIDS; pregnancy; and, childbirth. The five most deserving papers, based on the quality of the research and its presentation in written form, were selected for submission for publication. Dissemination of these research results is important. This publication shows what was learned from these five studies but it also reveals just how much is still unknown to us. These papers present the best information available on the specific topics that they address. They also make clear the need for additional evidence-based research on the sexual and reproductive health of young people in Latin America.

The four articles in this special section present results from original research projects designed to increase the understanding of a particular health phenomenon (sexual and reproductive health) in a particular population (young people aged 15 to 24), in a particular geographic region (Latin America). The authors of the articles are social scientists; their investigations rely heavily on the collection of qualitative data. Qualitative studies such as these provide information needed to inform policy and to improve interventions in the countries where the studies took place. The objective of such research is to help make programs which are designed to meet the needs of socially and culturally diverse groups of young people to successfully effectuate behavior changes that decrease the occurrence of unsafe sexual practices.

Studies addressing the sexual and reproductive health of young people, particularly in developing countries like those studied here, are important for many reasons. Young people are an important demographic group; there are approximately 1.2 billion young people in the world today and $85 \%$ of them live in developing countries. ${ }^{1}$ The demographic importance of the 15 to

\footnotetext{
* Argentina (3); Brazil (2); Colombia (2); Cuba (3); Mexico (2); Paraguay (1); and Peru (2).
}

24 year old age group is expected to increase in the $21^{\text {st }}$ century as its numbers continue to grow. ${ }^{2}$

Young people are an at risk group with respect to sexual and reproductive health issues. ${ }^{3}$ Trend data show that age at marriage for both young men and young women is rising in almost all countries in the world and age at first sexual intercourse is trending in the other direction. ${ }^{4}$ These trends imply an increased likelihood of premarital sexual activity. ${ }^{4}$ Studies suggest that many young people engage in premarital sexual activities that are unsafe including early sexual debut, infrequent use of contraceptives at sexual debut, multiple and casual partners, contact with sex workers and inconsistent use of condoms and other contraceptives. ${ }^{5,6}$ In so doing, they expose themselves to the health risks associated with unsafe sexual behaviors ${ }^{7}$ including unintended pregnancy and contracting sexually transmitted infections (STIs) and HIV/AIDS. An understanding of the range of political, economic, social and cultural realities that young people experience across and within societies ${ }^{7}$ is required if the sexual and reproductive health needs of diverse groups of young people are to be adequately addressed.

\section{The Latin American Region}

This section provides an overview of sexual and reproductive health issues in Latin America and is followed by a discussion of these issues in the three countries of study. Understanding regional trends provides a general context for the discussion of individual countries and understanding country trends provides a general context for the discussion of individual case studies. These case studies support the notion that it is essential to look behind the general trends and to understand specific contexts in order to make policy and intervention programs more effective.

A trend towards increased pre-marital sexual activity in Latin America was recently confirmed through analysis of Demographic and Health Surveys (DHS) data calendar data obtained from young single women (15 to 24 years of age) in eight Latin American countries (Bolivia, Brazil, Colombia, Dominican Republic, Guatemala, Nicaragua, Paraguay, Peru). ${ }^{8}$ The authors found that the prevalence of virginity is declining and that there is a concomitant trend towards increased uptake of contraception, especially condom use. The data suggest that contraceptive protection and conception rates are linked, e.g., Brazil and Colombia, the two countries with the highest contraceptive prevalence, had the lowest conception rates. Despite this, the authors conclude that the increase in contraceptive use shown in the data was 
not sufficient to hinder the increased risk of pregnancy associated with increased sexual activity. ${ }^{8}$

The increase in pre-marital sexual activity by young people in the Latin American region and the still limited use of contraception exposes the sexually active to the risks associated with unsafe sex. A study in Brazil from the 1990s found that almost $30 \%$ of sexually active adolescent males living in low-income areas had had an STI at least once. ${ }^{9}$ Another matter of great concern is the fact that the AIDS virus in Latin America is increasingly spreading to younger populations, especially young women. ${ }^{7}$ Data on the distribution of AIDS cases in Southern Cone countries indicates that the epidemic is shifting towards younger populations. ${ }^{10}$ Of the estimated 560000 young people (15 to 24 years of age) infected with HIV/AIDS in the Latin American region, approximately $69 \%$ are male and $31 \%$ are female. ${ }^{10}$

The adolescent fertility rate varies by country. The rates are highest (over 100 births per 1000 women 15 to 19 years of age) in Central American countries except Costa Rica. Other countries like Brazil, Colombia, Paraguay and Peru have rates between 75 and 100 births per 1000 while the rate in Argentina is below 75 per $1000 .^{3}$ Trend data suggest that while the total fertility rate has declined in most countries in Latin America, the decline is not reflected by a decline in adolescent fertility; ${ }^{3}$ the adolescent fertility rate has remained the same (e.g., in Peru) or has increased (e.g., in Argentina and Brazil). ${ }^{3}$

Many sexually active unmarried young women in the Latin American region become pregnant; data suggest that 12 to $25 \%$ of adolescents who give birth are unmarried. ${ }^{2}$ Combined data on unwanted pregnancies and abortions suggest that in Brazil, Colombia and Peru approximately 30 to $40 \%$ of adolescent pregnancies are unwanted..$^{3}$ Abortion is highly restricted and therefore clandestine in most countries in the region ${ }^{11}$ making accurate measurement challenging. Using data on hospitalizations for abortion complications, the Alan Guttmacher Institute estimated that in 1995 in Brazil, Colombia and Peru 23 to $30 \%$ of adolescent pregnancies ended in abortion. ${ }^{12}$

Unsafe abortion is an important contributor to maternal mortality in the Latin American region and maternal mortality is among the leading causes of death for adolescents. ${ }^{11}$ Also complicating matters is the fact that adolescents tend to delay seeking abortion services leading to later-term abortions with increased risk of complications. ${ }^{11}$ A study of data from the 1980s for six Latin American countries showed that women less than 20 years of age accounted for between 14 and $40 \%$ of women hospitalized for abortion complications. ${ }^{13}$

Adolescents in Latin America are also at risk of sexual coercion. A macro international study in Nicara- gua found that $26 \%$ of adolescent girls had experienced some type of physical or sexual violence. ${ }^{11}$ In Costa Rica, a study suggested that a high percentage of pregnancies among girls aged 15 or younger were due to incest. ${ }^{11}$ Studies in Peru show 50\% of young women reported that their first sexual encounter occurred under pressure or coercion. ${ }^{2}$

As this overview suggests, readily available data on the sexual and reproductive health of young people in the Latin American region are limited. The available data show general trends, e.g., increasing pre-marital sexual activity, an increasing number of HIV/AIDS cases in younger populations, steady or increasing rates of adolescent fertility and high rates of unwanted pregnancy and unsafe abortion. The data also suggest that sexual coercion may be a risk faced by young people throughout the region.

Data does not appear to be available at the regional or country level on the specific issues addressed by the papers presented here (i.e. young people's knowledge about STIs and HIV/ AIDS, the routine use of medical procedures during childbirth, quality of care issues at youth obstetrics services, the role of young men in couple formation, pregnancy and the adoption of contraceptive practices, or the perspectives of gynecologists and obstetricians about family planning and public policies on abortion). The dearth of available evidence underscores the need for this publication. Research on topics such as these is critical to understanding the factors that underlie the general trends outlined above. Such research is gathered primarily through individual micro level research projects. Micro level studies thus contribute to the development of a body of research that will provide insight and a better understanding of the general trends.

\section{The study countries: Argentina, Brazil and Peru}

The articles in this special section cover three Latin American countries: Argentina, Brazil and Peru. Table I provides selected health indicators and Table II provides selected reproductive health indicators for the study countries. In each of the three countries, approximately $30 \%$ of the population is aged 10 to 24 . The average age at first marriage is between 21 and 23 years of age. The percentage of single sexually active adolescent women ranges from $2.2 \%$ in Peru to $8.8 \%$ in Brazil. Over $30 \%$ of women in Brazil and Peru give birth before age 20. The contraceptive prevalence rates for single adolescents exceed the rates for married adolescents in all three countries. The contraceptive prevalence rates plummet if only modern methods are considered, particularly for 
Table I

\section{Selected INDICATORS FOR STUdY COUNTRIES}

\begin{tabular}{lrrr} 
Selected indicators & Argentina & Brazil & Peru \\
Population in millions & 37.9 & 174.7 & 26.5 \\
\hline Proportion urban & 88.5 & 82.2 & 73.5 \\
\hline Total fertility rate & 2.4 & 2.2 & 2.6 \\
\hline Literacy rate & 97.0 & 86.0 & 90.6 \\
\hline Maternal mortality rate & 35.0 & 55.8 & 185.0 \\
\hline $\begin{array}{l}\text { Proportion of deliveries attended by } \\
\text { trained personnel }\end{array}$ & 97.9 & 97.0 & 59.3 \\
\hline Physicians per 10,000 inhabitants ratio & 26.8 & 14.0 & 10.3
\end{tabular}

Source: PAHO website: www.paho.org Core Health Data. Updated as of 2002

single adolescents in Peru (33\%) suggesting significant reliance on traditional methods. The HIV prevalence for males aged 15 to 24 exceeds the rate for females of the same age in all countries.

\section{WH॰ case studies}

The five articles in this special edition tackle difficult and challenging issues related to the sexual and reproductive health of young people. The study from Peru compares Peruvian adolescents from three culturally different localities in terms of their knowledge about STIs and
HIV/AIDS. The respondents aged 13 to 19 were secondary school students who took the sex education courses offered in the public school system. The researcher collected data by using semi-structured interviews and focus group discussions. The study finds that Peruvian adolescents have only superficial knowledge of STIs and HIV/AIDS and that, while they know that they should protect themselves, they fail to do so. School was cited as the most frequent source of information on these topics but students complained about the quality of the sex education program.

The study from Brazil takes a thorough look at the routine use of four technological procedures during vaginal births in public sector hospitals. It investigates users' and caregivers' perspectives on the use of trichotomy, episiotomy, oxytocin infusion and epidural analgesia during the birth process. ${ }^{*}$ The investigators collected data using participant observation, semi-structured interviews with women aged 15 to 24, administration of a structured questionnaire to hospital staff working with young patients and in-depth interviews with select health care professionals. The study finds that users' and caregivers' perspectives and the meanings they attach to the use of these procedures differ. The

* Trichotomy is the shaving of the pubic hair; Episiotomy is a cut administered to the perineum shortly before expulsion of the baby; Oxytocin is a hormone used to induce or speed up labor; and Epidural Analgesia is a spinal injection that numbs from the waist down.

Table II

REPRODUCTIVE HEALTH INDICATORS FOR STUDY COUNTRIES

\begin{tabular}{|c|c|c|c|}
\hline & Argentina & Brazil & Peru \\
\hline Population aged I0-24 (\% of total), 2000 & 27 & 30 & 31 \\
\hline Average age at first marriage women $15-49$ & 23 & 21 & 21 \\
\hline Currently married women I5-19 (\%) & 10 & 14 & 12 \\
\hline Single sexually active women $15-19(\%)$ & $\mathrm{N} / \mathrm{A}$ & 8.8 & 2.2 \\
\hline Women giving birth by age 20 (\%) & $\mathrm{N} / \mathrm{A}$ & 32 & 32 \\
\hline Contraceptive prevalence:Any method women I5-49 (\%) & $\mathrm{N} / \mathrm{A}$ & 77 & 69 \\
\hline Contraceptive prevalence:Any method single women $15-19$ (\%) & $\mathrm{N} / \mathrm{A}$ & 66 & 70 \\
\hline Contraceptive prevalence:Any method married women I5-19 (\%) & $\mathrm{N} / \mathrm{A}$ & 54 & 46 \\
\hline Contraceptive prevalence: Modern methods women I5-49 (\%) & N/A & 70 & 50 \\
\hline Contraceptive prevalence: Modern methods single women I5-19 (\%) & N/A & 61 & 33 \\
\hline Contraceptive prevalence: Modern methods married women I5-19 (\%) & N/A & 47 & 31 \\
\hline HIV prevalence rate:Age I5-24 male (\%) & 0.85 & 0.64 & 0.42 \\
\hline HIV prevalence rate:Age I5-24 female (\%) & 0.34 & 0.48 & 0.18 \\
\hline
\end{tabular}

Sources: Population Reference Bureau DataFinder (www.prb.org/datafind); UNFPA State of the World Population 2003 
study also finds that routine practices do not coincide with best medical practices, as these are viewed as being inapplicable to the public hospital context or in conflict with institutional constraints.

The first study from Argentina compares the quality of sexual and reproductive health care that adolescents receive in a general obstetrics service and in one specialized in serving adolescents. The investigator interviewed doctors who provide services to adolescents in public hospitals in Buenos Aires and interviewed and administered a survey to adolescent users of the services aged 15 to 19 years. The findings suggest that adolescents receive better and more personal care in a service specializing in serving adolescents. Moreover, the study found that there is a great need for hospital level norms and their effective implementation.

A second study from Argentina provides insight into the role of young men in couple formation, pregnancy and adoption of contraceptive practice. The investigator used semi-structured interviews with 60 young people aged 18 to 30 from two socio-economic groups (low and middle income) who were in a consensual union or married and had at least one child. The study finds that in the lower income strata young fatherhood is more valued than in the middle income strata. For young, poor men, adolescent fatherhood represents a transition to adulthood and greater autonomy. For young men of middle income, early pregnancy is seen to conflict with personal aspirations, particularly professional aspirations.

A third study from Argentina investigates the perspectives of obstetricians and gynecologists with regard to public policy on family planning and abortion. The researchers administered a survey, conducted semi-structured interviews and held focus group discussions with obstetricians and gynecologists. Historically doctors in Argentina have played a very limited role in political processes related to sexual and reproductive health. The study finds that these doctors consider fertility regulation of high public health importance and a priority action for government programs and services. The doctors also consider abortion of high public health importance and many favor broader exceptions for abortion than those currently permitted by law. However, the doctors were apprehensive about participating publicly in the political process due to perceived social and professional repercussions.

\section{Gonclusions}

The five articles in this special edition help to improve our understanding of the factors that contribute to risky sexual behavior and negative reproductive health outcomes among youth in Latin America. A review of the studies reveals findings with high policy and programmatic relevance. For example, the findings from Peru suggest that the national sex education program has the potential to be an important source of accurate information on sexual and reproductive health related topics, but that, in its current state fails in its mission. The author suggests that, taking Peru's multicultural and bilingual context into account, the content of the program be modified to provide the information adolescents want and need.

The authors of the article on Brazil argue in favour of a "humanization" of the child delivery process that can only be achieved if the cultural meanings attached to the procedures by both women and health care professionals are taken into account in designing public policies. The Argentinean study on quality of care finds that health care professionals are not governed in their health care practice by hospital norms that reflect public policy recently adopted through legislative action and that there is a great need for such norms and their effective implementation.

The author of the Argentinean study on young men suggests that there are conflicts and tensions between the gender roles the young men learn in their families of origin and their own reproductive expectations, and recommends that health care services incorporate services aimed at helping young men to work out these conflicts. The authors of the Argentinean study on the role of doctors in public policy recommend advocacy work with the medical community to increase their participation in the political process.

\section{Recommendations}

The articles in this special edition address important but varied facets of the sexual and reproductive health needs of young people in Latin America. Awareness of infection, pregnancy related practices, quality of services and male involvement in sexual and reproductive health decisions represent just a few of the myriad health issues facing sexually active young people today. The findings suggest that research gaps remain. There is a need for more information about how to translate knowledge into behavior, how to provide sensitive and acceptable delivery practices, how to provide youth friendly quality of care and how to address gender roles and masculinity issues. There is also a need for more research addressing a broader spectrum of the sexual and reproductive health issues facing this population. In spite of the need for a more complete body of evidence, the findings reported here clearly have important implications for health care interventions aimed at young people. 
Past research suggests that interventions such as those proposed in Peru are more effective at improving knowledge than at actually changing behaviors. ${ }^{6,8}$ This implies that in addition to improving the knowledge and understanding of Peruvian adolescents, there is a need to better understand how improving their knowledge is linked to changing their behaviors. Education appears as a necessary but not sufficient factor contributing to behavior change. Further research could help us to better understand the complex interactions between education and other factors in particular social and cultural contexts. What is needed in addition to education? For example, what role does access to contraception play? And how can cultural beliefs and practices that appear to contradict safe sex practices be brought into harmony with safe sex practices? Or can they?

The findings of the Argentinean study on male gender roles hints at the relatively unexplored topic of "wanted" pregnancy, especially among young men of lower socio-economic status. These young men gain prestige and autonomy when they become fathers and fatherhood does not directly contradict their aspirations for the future. This means that there is a need for further research to better understand how wanted pregnancy impacts the sexual and reproductive behavior of adolescents. It also hints at the need for evidence-based interventions that promote healthy outcomes for adolescents who choose to have children.

The other three studies seek to inform policy at the hospital and/or legislative level. The Brazilian case and the Argentinean study on quality of care require a greater understanding of how public policy and hospital norms can be used to actually change doctors' behavior. This is similar to the question of education in the Peruvian example. What is the role of enforcement at the hospital level or, by government agencies? Are hospitals accountable and if not, what can be done to change that? Can medical school training be changed to promote greater compliance with public policy and/or hospital norms? How can discrepancies between what is taught, what ought to be done and what is done be avoided?

The observation by the authors of the Argentinean study that advocacy work should take place points to the need to better understand the barriers and stigma attached to participation and the need to understand how these can be overcome. It is imperative that the medical community contribute to public policy debate in areas where medical knowledge and expertise are directly relevant to the policy under consideration. The involvement of the medical community is of particular significance in controversial topics such as family planning and abor- tion. The regional overview provided above shows that these issues are of paramount importance to the sexual and reproductive health outcomes of young people. This population suffers from high rates of unwanted pregnancy indicating a great need for information and access to family planning services. Many unwanted pregnancies end in illegal abortions and complications from illegal abortions are a major contributor to maternal mortality. Thus, it is important to understand, in a situation where there is a trend of non-participation, whether it is due to an elitist (above the fray) attitude. Alternatively, is nonparticipation part of the professional culture? Are there really negative repercussions? And if so, what are they? Understanding the context in which doctors shy away from participation in the political process is needed to inform policies that would increase their participation.

The papers included in this volume are qualitative case studies; their findings are useful to inform health care interventions addressing the sexual and reproductive health needs of young people in differing contexts. The Peruvian study suggests sex education may be an important factor in influencing safe sex behavior, but to reach their full potential, sex education programs must be tailored to the needs of a specific audience. The Brazilian study reveals a great need for the humanization of services. When viewed in conjunction with the Argentinean study addressing hospital norms and their effective implementation, the implication is that hospital practices need to change and that greater accountability is needed to effectuate such change. The Argentinean study on the role of doctors in public policy debate suggests, on a larger scale, that the lack of participation by doctors in policy making may play a role in the lack of effective hospital norms and/or the failure to implement the norms that already exist. Finally, as the third Argentinean paper acknowledges, sexual and reproductive health services must address the needs of both young women and young men. Sexually active males and sexually active females face different sexual and reproductive health issues and both require adequate services to redress them.

\section{Acknowledgements}

I would like to acknowledge the Department of Reproductive Health and Research at the World Health Organization for making this project possible. In particular, I am grateful for the intellectual guidance and support received from Iqbal Shah and the moral and administrative support received from Nicky Sabatini-Fox. 


\section{References}

I. United Nations (Department of Economic and Social Affairs, Population Division).World Population Prospects. The 1998 Revision. Volume I: Comprehensive Tables. New York: United Nations 1999.

2. Blum, Robert W, Kristin Nelson-Mmari.The Health of Young People in a Global Context. J Adoles Health 2004: 35:402-4I8

3. Guzman JM, Falconier-de Moyano M, Hakkert R, Contreras JM. "Políticas de Población para Adolescentes: Diagnóstico de Situación y Políticas de Salud Sexual y Reproductiva". México: UNFAP.Working Papers Series CST/LAC No. 9, 2000

4.Van Look, Paul FA. On being an adolescent in the $21^{\text {st }}$ century. In Towards Adulthood: exploring the sexual and reproductive health of adolescents in South Asia. Eds. Bott S, Jejeebhoy S, Shah I, Puri C. Geneva/ RHR:WHO, 2003.

5.World Health Organization. Promoting the sexual and reproductive health needs and rights of adolescents. WHO/RHR Progress in Reproductive Health Research. 2002 Available at: www.who.int/ reproductive-health/hrp/progress/58/news $58 . h$ tml

6. Brown AD, Jejeebhoy SJ, Shah I,Yount KM. Sexual relations among young people in developing countries: evidence from WHO case studies. Geneva: World Health Organization, Department of Reproductive Health and Research,200I.
7. United Nations Population Fund. UNFPA State of World Population 2003. Making I Billion Count: Investing in Adolescents' Health and Rights. New York: UNFPA, 2003

8. Mohamed MA, Cleland J. Sexual and reproductive behavior among single women aged 15-24 in eight Latin American countries: a comparative analysis. Soc Sci Med 2005; 60: I I 75- I 185

9. Childhope. Gender, Sexuality, and Attitudes Related to AIDS among Low Income Youth and Street Youth in Rio de Janeiro, Brazil. New York, NY: Childhope, 1997.

10.Aggleton P, Chase E, Rivers K, Tyler P. Innovative Approaches to HIV Prevention: Selected Case studies Prepared for the Joint United Nations Programme on HIVIAIDS. Geneva: UNAIDS.; Joint United Nations Programme on HIVIAIDS (1997) "Impact of HIV and Sexual Health Education on the Sexual behavior of Young People:A Review Update. Geneva: UNAIDS, 2000.

I I. Schutt-Ainer J, Maddaleno M. Sexual Health and Development of Adolescents and Youth in the Americas: Program and Policy Implications. PAHO:Washington, DC, 2003.

12. Singh, S.Adolescent childbearing in developing countries: a global review. Stud Fam Plan 1998;29 (2): I I7-I36.

13.Alan Guttmacher Institute. Clandestine Abortion:A Latin American Reality. New York, NY:AGI, 1994. 